\title{
Investigation of cadmium-induced apoptosis and the protective effect of $N$-acetylcysteine in BRL 3A cells
}

\author{
XUEZHONG LIU ${ }^{1,2^{*}}$, YIRAN ZHANG ${ }^{1,2^{*}}$, YI WANG $^{1,2}$, YUAN YAN ${ }^{1,2}$, JIAJING WANG $^{1,2}$, \\ JIANHONG GU ${ }^{1,2}$, BIANJIAN CHUN ${ }^{1,2}$ and ZONGPING LIU ${ }^{1,2}$ \\ ${ }^{1}$ College of Veterinary Medicine, Yangzhou University; ${ }^{2}$ Jiangsu Co-Innovation Center for Prevention and \\ Control of Important Animal Infectious Diseases and Zoonoses, Yangzhou, Jiangsu 225009, P.R. China
}

Received March 27, 2015; Accepted December 30, 2015

DOI: $10.3892 / \mathrm{mmr} .2016 .5218$

\begin{abstract}
The aims of the present study were to investigate the effect of cadmium $(\mathrm{Cd})$-induced apoptosis and determine the protective effect of $N$-acetylcysteine (NAC) in BRL 3A cells. The BRL 3A cells were treated with $0,10,20$ or $40 \mu \mathrm{mol} / 1$ cadmium acetate $\left(\mathrm{CdAc}_{2}\right)$ for $12 \mathrm{~h}$. Another two groups of cells were preincubated with $2 \mathrm{mmol} / 1 \mathrm{NAC}$ for $30 \mathrm{~min}$, and then either incubated with $20 \mu \mathrm{mol} / 1 \mathrm{CdAc}_{2}$ for $12 \mathrm{~h}$, or treated with NAC alone. The levels of apoptosis and mitochondrial membrane potential $(\Delta \Psi \mathrm{m})$ were measured using flow cytometry. Mitochondrial ultrastructural changes were detected using transmission electron microscopy. The protein levels of caspase-3, caspase-9, poly (ADP-ribose) polymerase (PARP), caspase-8, and Fas ligand (FasL) protein were measured using immunoblotting. As the dose of $\mathrm{Cd}$ increased, there was a significant increase in the apoptotic ratio, a significant decrease in $\Delta \Psi \mathrm{m}$, mitochondrial swelling and degeneration, and blurring, deformation and eventual collapse of the mitochondrial cristae. The protein levels of caspase-3, caspase-9 and PARP decreased, whereas the levels of cleaved caspase-3, cleaved caspase-9, cleaved caspase- 8 and FasL increased dose-dependently in relation to $\mathrm{Cd}$. NAC effectively inhibited these changes. $\mathrm{Cd}$ induced apoptosis through the mitochondrial and FasL pathways in the BRL 3A cells, and NAC exerted a protective effect against $\mathrm{Cd}$-induced damage.
\end{abstract}

\section{Introduction}

Cadmium (Cd) is a toxic heavy metal, which is present in the air, soil, sediment and water. $\mathrm{Cd}$ causes injury to a number

Correspondence to: Dr Zongping Liu, College of Veterinary Medicine, Yangzhou University, 88 South University Avenue, Yangzhou, Jiangsu 225009, P.R. China

E-mail: liuzongping@yzu.edu.cn

*Contributed equally

Key words: cadmium acetate, BRL 3A cells, apoptosis, $\mathrm{N}$-acetylcysteine, mitochondria, Fas ligand pathway of organs and tissues, and induces dysfunction, including in the kidney, liver, lung, bone, cardiovascular system and immune system. Cd pollution originates from mining, metallurgical industries, and the manufacture of nickel-Cd batteries, pigments and plastic stabilizers. The Agency for Toxic Substances and Disease Registry has classified Cd as the sixth most toxic substance to human health (1).

Numerous studies have revealed that $\mathrm{Cd}$ induces apoptosis in several types of cells and tissues $(2,3)$. Mitochondria are the early and primary targets of Cd injury (4), with exposure to $\mathrm{Cd}$ inducing mitochondria-dependent apoptosis in oligodendrocytes, and the mitochondria are crucial in coordinating caspase activation through the release of cytochrome $c$ (Cyt C). A previous study (5) reported that $\mathrm{Cd}$ induces apoptosis in tumor cells through the Fas/Fas ligand (FasL) pathway. The Fas/FasL pathway is an important apoptosis signal transduction pathway, in which ligand-receptor interaction activates the cell death pathway. As a member of the tumor necrosis factor family, Fas is a $45-\mathrm{kDa}$ type I transmembrane protein, which induces apoptosis in susceptible cells by crosslinking with its ligand. Following the trimerization of Fas on the cell membrane by extracellular FasL, the Fas-associated death domain and caspase- 8 form a death-inducing signal complex, which mediates Fas-induced cell death. Once activated, caspase- 8 activates effector caspases, including caspase-3, caspase- 6 and caspase-7, ultimately leading to the hydrolysis of cytosolic and nuclear substrates.

$\mathrm{N}$-acetylcysteine (NAC), formed of 1-cysteine and acetyl, is the precursor of reducing glutathione in cells. As a thiol donor, NAC is an effective antioxidant has effects including interference of free radical generation and scavenging of generated free radicals, resistance to apoptosis, preventing DNA damage, anti-angiogenesis, regulation of gene expression and signal transduction, and inhibiting malignant tumor development (6). NAC has been widely used clinically and experimentally, and exerts effects in the respiratory system (7), cardiovascular system (8) and central nervous system (9). It is reported that NAC can effectively inhibit the apoptosis induced by $\mathrm{Cd}$ in macrophage (10) and human lens epithelial cells (11). Repeated application in severe early sepsis showed that NAC can effectively inhibit the apoptosis of pulmonary dendritic cells, protecting the function of the cells (7). In severe sepsis, the early repeated application of NAC effectively inhibits lung 
dendritic cell apoptosis. NAC can also effectively regulate respiratory apoptosis in rats caused by smoking, and at as a cancer chemopreventive agent (12).

Although there have been previous investigations on Cd-induced injury, its mechanism remains to be fully elucidated. The liver is the primary target organ of Cd injury $(13,14)$. Therefore, the present study used cytobiological and molecular biological methods to examine the mechanism of Cd-induced apoptosis involving the mitochondrial and FasL pathways, and investigated the protective effect of NAC, in immortalized rat BRL 3A hepatocytes.

\section{Materials and methods}

Materials. Cadmium acetate $\left(\mathrm{CdAc}_{2}\right)$, penicillin, streptomycin, gluteraldehyde, osmium textroxide, propylene oxide, epoxy resin, uranyl acetate, lead citrate, sodium dodecyl sulfate (SDS), tris-buffered saline with $0.1 \%$ Tween-20 (TBST) were purchased from Sigma-Aldrich (St. Louis, MO, USA). Annexin V-fluorescein isothiocyanate (FITC) Apoptosis Selection Kit I was purchased from BD Pharmingen (San Diego, CA, USA). Dulbecco's modified Eagle's medium (DMEM) and fetal bovine serum (FBS) were obtained from Gibco (Thermo Fisher Scientific, Inc., Waltham, MA, USA). Trypsin was purchased from Amresco LLC (Solon, OH, USA). The Mitochondrial Membrane Potential Assay Kit with JC-1, and bicinchoninic acid (BCA) protein assay kits were from Beyotime Institute of Biotechnology (Jiangsu, China). Rabbit anti-rat polyclonal caspase-3 (1:1,000; cat. no. 9662), rabbit anti-rat polyclonal caspase-9 (1:1,000; cat. no. 9506), rabbit anti-rat polyclonal poly(ADP-ribose)polymerase (PARP) (1:1,000; cat. no. 9542), rabbit anti-rat monoclonal caspase-8 (1:1,000; cat. no. 4790), rabbit anti-rat polyclonal FasL (1:1,000; cat. no. 4273), and rabbit anti-rat polyclonal $\beta$-actin (1:5,000; cat. no. 4967) antibodies, and horseradish peroxidase (HRP)-conjugated goat anti-rabbit immunoglobulin G (IgG) $(1: 5,000$; cat. no. 7074) were obtained from Cell Signaling Technology, Inc. (Danvers, MA, USA).

Radioimmunoprecipitation assay (RIPA) lysis buffer was purchased from Beijing Solarbio Science \& Technology (Beijing, China). Kodak X-ray film was purchased from Eastman Kodak (Rochester, NY, USA). Cell culture plates were obtained from Corning Incorporated (New York, NY, USA). Nitrocellulose (NC) filter membranes were purchased from Pall Gelman Sciences (Port Washington, NY, USA). The enhanced chemiluminescence (ECL) detection kit was from Thermo Fisher Scientific, Inc. (Pierce ECL Plus Western Blotting Substrate). Other reagents used were available locally and of analytical grade.

Cell culture and treatments. In the present study, BRL 3A immortalized rat liver cells between passages 10 and 20 were used (Chinese Academy of Sciences, Shanghai, China). The cells were cultured in DMEM supplemented with $100 \mathrm{U} / \mathrm{ml}$ penicillin, $100 \mu \mathrm{g} / \mathrm{ml}$ streptomycin and $10 \% \mathrm{FBS}$, and maintained at $37^{\circ} \mathrm{C}$ in a $5 \% \mathrm{CO}_{2}$ humid incubator (Thermo Fisher Scientific, Inc.).

The BRL 3A cells $\left(2 \times 10^{5}\right.$ cells $\left./ \mathrm{ml}\right)$ were seeded in 6 - or 96-well plates. $\mathrm{CdAc}_{2}$ was dissolved in distilled deionized water as a stock solution $(5 \mathrm{mM})$, and diluted with serum-free culture medium to different concentrations prior to being added to the cell cultures.

The cells were treated with $0,10,20$ or $40 \mu \mathrm{mol} / 1 \mathrm{Cd}$ for $12 \mathrm{~h}$ (groups a-d, respectively). In another two experiments, the cells were preincubated with $2 \mathrm{mmol} / 1 \mathrm{NAC}$ for $30 \mathrm{~min}$, prior to $12 \mathrm{~h}$ incubation with $20 \mu \mathrm{mol} / 1 \mathrm{Cd}$, or incubation with $2 \mathrm{mmol} / \mathrm{l} \mathrm{NAC}$ alone for $12 \mathrm{~h}$ (groups e and f, respectively). At each stage, cells were incubated at $37^{\circ} \mathrm{C}$ in $5 \% \mathrm{CO}_{2}$.

Detection of apoptosis. Apoptosis was detected using the apoptosis detection kits, according to the manufacturer's protocols. Following treatment, the cells were harvested and resuspended in $100 \mu \mathrm{l}$ binding buffer containing $5 \mu \mathrm{l}$ annexin V-FITC and $5 \mu \mathrm{l}$ propidium iodide (PI) solution. Following incubation in the dark at $25^{\circ} \mathrm{C}$ for $15 \mathrm{~min}, 400 \mu \mathrm{l}$ binding buffer was added. The cells were analyzed using a FACSAria flow cytometer (Becton Dickinson, San Jose, CA, USA) with excitation and emission wavelengths of 488 and $605 \mathrm{~nm}$, respectively. A minimum of 10,000 cells per sample were registered. Positioning of quadrants on the annexin V-/PI dot plots was performed, and living (annexin $\mathrm{V}^{-} / \mathrm{PI}^{-}$), early apoptotic (annexin $\left.\mathrm{V}^{+} / \mathrm{PI}\right)$, late apoptotic (annexin $\mathrm{V}^{+} / \mathrm{PI}^{+}$) and necrotic cells (annexin $\mathrm{V}^{-} / \mathrm{PI}^{+}$) were distinguished. The total proportion of apoptotic cells comprised the percentage of cells with annexin $\mathrm{V}^{+} / \mathrm{PI}^{-}$and annexin $\mathrm{V}^{+} / \mathrm{PI}^{+}$fluorescence (15).

Each independent experiment included another three samples: Unstained, annexin V-FITC staining only, and PI staining only, as controls. Each experiment was repeated at least three times.

Determination of mitochondrial membrane potential $(\Delta \Psi \mathrm{m})$. The fluorescent probe, JC-1, was used to measure the $\Delta \Psi \mathrm{m}$ of the BRL 3A cells. JC-1 is a cationic dye, which accumulates in the mitochondria according to the $\Delta \Psi \mathrm{m}$. If the $\Delta \Psi \mathrm{m}$ is high, JC-1 aggregates in the mitochondrial matrix, forming J-aggregates, which generate red fluorescence (16). If the $\Delta \Psi \mathrm{m}$ is lost, JC-1 remains in a monomeric form, generating green fluorescence. The relative ratio of red $(590 \mathrm{~nm})$ and green $(525 \mathrm{~nm})$ fluorescence intensity provides the proportional measurement of the $\Delta \Psi \mathrm{m}$.

The cells $\left(5 \times 10^{5}\right)$ were incubated with $0.5 \mathrm{ml} 1 \mathrm{X} \mathrm{JC}-1$ at $37^{\circ} \mathrm{C}$ for $20 \mathrm{~min}$ in the dark, and were centrifuged at $2,000 \mathrm{xg}$ for $4 \mathrm{~min}$ at $4^{\circ} \mathrm{C}$. The cells were then washed twice with $1 \mathrm{X} \mathrm{JC}-1$ buffer, resuspended in $1 \mathrm{ml} 1 \mathrm{X}$ JC-1 buffer, and analyzed immediately using flow cytometry.

Observation of mitochondrial ultrastructure. The changes in mitochondrial ultrastructure were confirmed by transmission electron microscopy (TEM) examination using the method previously described by Yuan et al (17). Briefly, the cell suspensions $\left(1 \times 10^{7}\right.$ cells $\left./ \mathrm{ml}\right)$ were centrifuged at $2,000 \times \mathrm{g}$ for $5 \mathrm{~min}$ at $4^{\circ} \mathrm{C}$ following treatment and the medium was discarded. The cells were then fixed with $200 \mu 12.5 \%$ glutaraldehyde in phosphate-buffered saline (PBS) at $25^{\circ} \mathrm{C}$ for $24 \mathrm{~h}$. Following fixing, the cells were washed three times with PBS and post-fixed for $1.5 \mathrm{~h}$ in $1 \%$ osmium tetroxide. The specimens were dehydrated using a graded series of ethanol (75, 85,95 and $100 \%$ ), rinsed in propylene oxide, and impregnated with epoxy resin. Ultrathin sections $(70 \mathrm{~nm})$ were obtained and contrasted with uranyl acetate and lead citrate. Electron 
A a

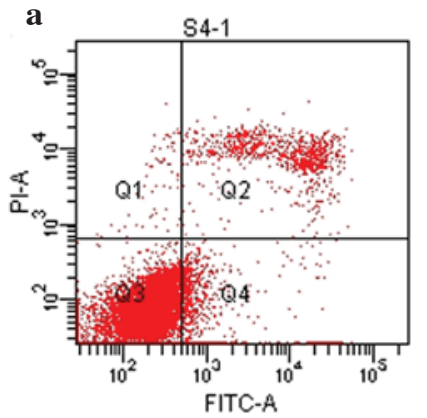

d

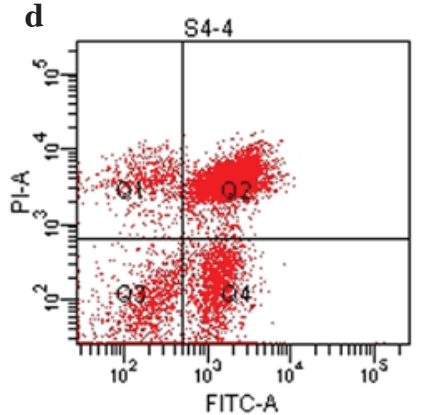

b

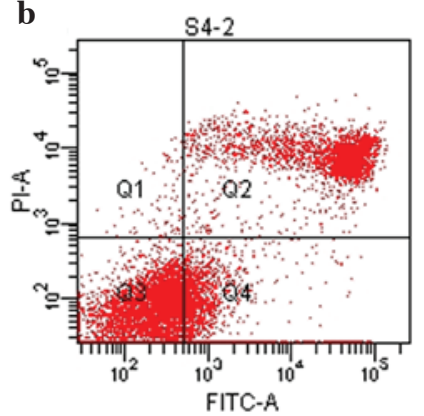

e

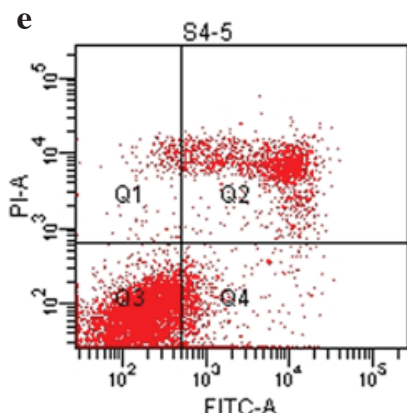

c

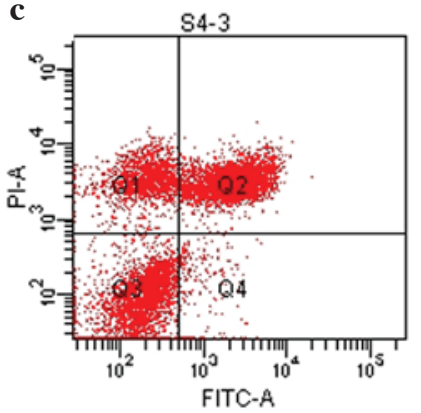

f

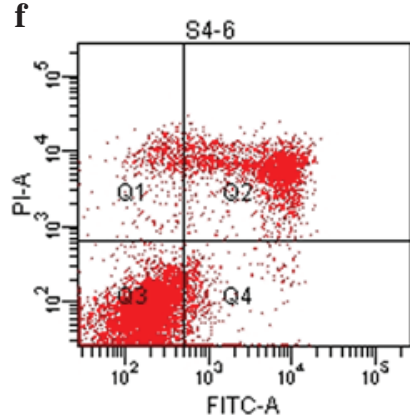

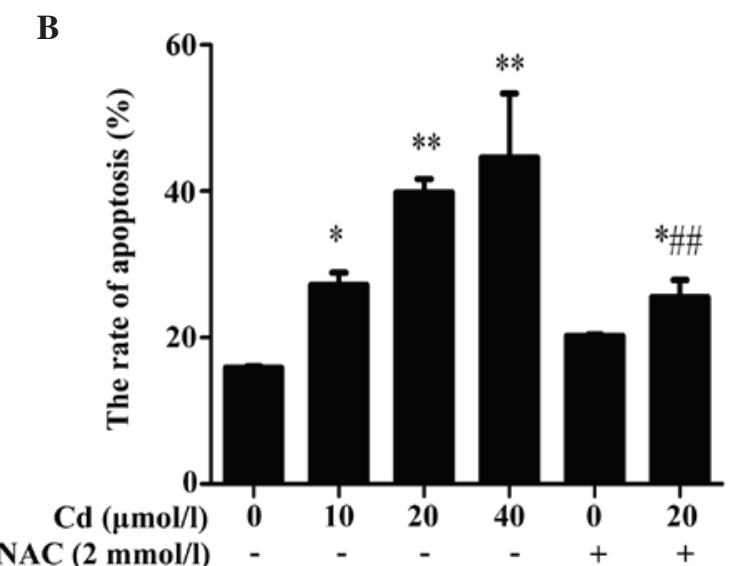

Figure 1. (A) Apoptotic effect of $\mathrm{Cd}$ and the protective effect of NAC in BRL $3 \mathrm{~A}$ cells. (a) Control; (b) $10 \mu \mathrm{mol} / \mathrm{L} \mathrm{Cd}$; (c) $20 \mu \mathrm{mol} / 1 \mathrm{Cd}$; (d) $40 \mu \mathrm{mol} / 1 \mathrm{Cd}$; (e) $2 \mathrm{mmol} / 1 \mathrm{NAC}$; (f) $2 \mathrm{mmol} / 1 \mathrm{NAC}+20 \mu \mathrm{mol} / \mathrm{l} \mathrm{Cd}$. (B) Effect of Cd on the rates of apoptosis and the protective effect of NAC in BRL 3A cells. The Cd-induced apoptotic rate increased significantly, in a concentration-dependent manner, compared with the control. NAC significantly reduced the rate of Cd-induced apoptosis. Data are presented as the mean \pm standard deviation. ${ }^{*} \mathrm{P}<0.05$ and ${ }^{* *} \mathrm{P}<0.01$, compared with the control; ${ }^{\# \#} \mathrm{P}<0.01$, compared with $20 \mu \mathrm{mol} / 1 \mathrm{Cd}$ alone. Cd, cadmium; NAC, $N$-acetylcysteine; FITC, fluorescein isothiocyanate; PI, propidium iodide.

micrographs were captured using a CM-100 TE microscope (Philips, Eindhoven, the Netherlands).

Western blotting. Following treatment, the cells were washed twice with cold PBS, and lysed in RIPA lysis buffer on ice for $30 \mathrm{~min}$, followed by sonication at $3 \mathrm{~W}$ for $15 \mathrm{sec}$. The cell lysates were then centrifuged at $12,000 \mathrm{x}$ g for $10 \mathrm{~min}$ at $4^{\circ} \mathrm{C}$. The protein content was determined using the BCA protein assay kit, and the absorbance was measured at $560 \mathrm{~nm}$ using a microplate reader (BioTek Instruments, Inc., Winooski, VT, USA). Aliquots of the lysate were diluted in 6X SDS sample buffer and boiled for $10 \mathrm{~min}$. The protein $(30 \mu \mathrm{g})$ from each treatment group was separated on a $12 \%$ SDS-polyacrylamide gel and electrophoretically transferred onto NC membranes. Following blocking at room temperature for $2 \mathrm{~h}$ with $5 \%$ non-fat milk in $0.1 \%$ TBST, the membranes were incubated overnight at $4^{\circ} \mathrm{C}$ with the corresponding primary antibodies to caspase-3, caspase-9, PARP, caspase-8, FasL $(1: 1,000)$ and $\beta$-actin $(1: 5,000)$. Following washing with TBST (six times, 5 min each), the membranes were incubated with HRP-conjugated goat anti-rabbit $\operatorname{IgG}(1: 5,000)$ at room temperature for $2 \mathrm{~h}$. Following washing with TBST (six time, 5 min each), the blots were visualized using the ECL detection kit, according to the manufacturer's protocol, and were then exposed to X-ray film.

Statistical analysis. The results are presented as the mean \pm standard deviation. Significance was assessed using one-way analysis of variance, following appropriate transformation to normalized data and equalized variance, where necessary. Statistical analyses were performed using SPSS version 17.0 (SPSS Inc., Chicago, IL, USA); $\mathrm{P}<0.05$ was considered to indicate a statistically significant difference. All assays were performed in triplicate. 


\section{Results}

Cd induces apoptosis and is reversed following preincubation with NAC. In the present study, flow cytometry was used to distinguish the effects of $\mathrm{Cd}$ on apoptosis following annexin V-FITC/PI double staining. Following $12 \mathrm{~h}$ incubation with Cd (10, 20 and $40 \mu \mathrm{mol} / \mathrm{l})$, the percentages of total (early+late) apoptotic cells increased significantly to $27.2 \pm 1.65,39.83 \pm 1.82$ and $44.57 \pm 8.81 \%$, respectively, compared with the control $(15.87 \pm 0.21 \%)$, indicating that $\mathrm{Cd}$ induced apoptosis in the BRL 3A cells. NAC alone did not alter the rate of apoptosis significantly, compared with the control. However, preincubation with NAC reduced the rate of $\mathrm{Cd}$-induced apoptosis, compared with that induced by $\mathrm{Cd}$ alone (Fig. 1).

Cd reduces $\triangle \Psi_{m}$ and is increased by preincubation with NAC. The $\Delta \Psi \mathrm{m}$ decreased following $12 \mathrm{~h}$ exposure to $\mathrm{Cd}$, which occurred in a dose-dependent manner (Fig. 2). Preincubation with NAC improved the Cd-induced decrease in $\Delta \Psi \mathrm{m}$, compared with the decrease induced by $\mathrm{Cd}$ alone.

Effects of Cd and NAC on BRL $3 A$ cell ultrastructure. The results of the TEM examination showed that, $12 \mathrm{~h}$ following exposure to $\mathrm{Cd}$, the control cells had a well-defined outline and contained spherical or oval mitochondria, with well-defined transversal cristae. By contrast, the cells incubated with $\mathrm{Cd}$ exhibited changes in mitochondrial ultrastructure, including disruption and loss of cristae, swelling and degeneration, vacuole formation in the cytoplasm, and cell plasma membrane disruption. NAC alone did not alter the cell ultrastructure significantly, compared with the control. However, preincubation with NAC reduced the mitochondrial swelling induced by $\mathrm{Cd}$, compared with that induced by $\mathrm{Cd}$ alone (Fig. 3).

Cd decreases the protein expression levels of caspase-3, caspase-9 and PARP, which is attenuated by preincubation with NAC. The protein levels of caspase-3, caspase-9 and PARP decreased as the Cd dose increased, whereas the levels of cleaved caspase-3 and cleaved caspase-9 increased (Fig. 4). NAC alone did not affect the protein levels; preincubation with NAC prior to Cd treatment inhibited the tendency of the protein levels to change, compared with the changes induced by $\mathrm{Cd}$ alone.

Cd increases the protein expression levels of caspase- 8 and FasL, which is attenuated by preincubation with NAC. The results of the Western blotting revealed that $12 \mathrm{~h}$ treatment with Cd significantly elevated the protein levels of cleaved caspase- 8 and FasL in the BRL 3A cells (Fig. 5), whereas preincubation with NAC prior to $\mathrm{Cd}$ treatment inhibited the tendency of the protein levels to increase.

\section{Discussion}

It has been suggested that $\mathrm{Cd}$ can cause apoptosis in a variety of cells, and can occur in a dose- and time-dependent manner (18). Pathak and Khandelwal (19) reported that $6 \mathrm{~h}$ exposure to $25 \mu \mathrm{mol} / 1 \mathrm{Cd}$ induced apoptosis in rat thymus cells. Chen et al (20) reported that Cd caused apoptosis in PC12 and SH-SY5Y nerve cells, in a dose-dependent manner.

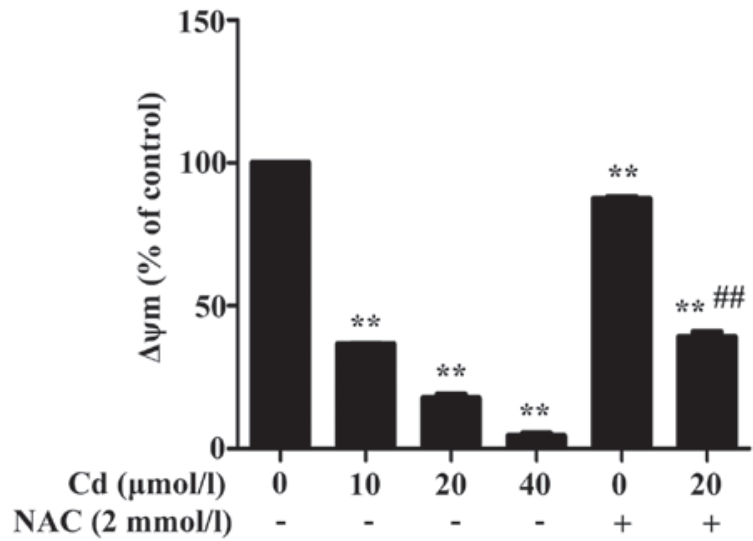

Figure 2. Effect of $\mathrm{Cd}$ and NAC on $\Delta \Psi \mathrm{m}$ in BRL $3 \mathrm{~A}$ cells. The $\Delta \Psi \mathrm{m}$ was significantly decreased by $\mathrm{Cd}$, in a dose-dependent manner. NAC significantly improved the $\mathrm{Cd}$-induced decrease in $\Delta \Psi \mathrm{m}$. Data are presented as the mean \pm standard deviation. ${ }^{* *} \mathrm{P}<0.01$, compared with the control; ${ }^{\# \#} \mathrm{P}<0.01$, compared with $20 \mu \mathrm{mol} / 1 \mathrm{Cd}$ alone. $\Delta \Psi \mathrm{m}$, mitochondrial membrane potential; Cd, cadmium; NAC, $N$-acetylcysteine.

In the present study, flow cytometry demonstrated that all concentrations of $\mathrm{Cd}$ induced a significantly higher rate of apoptosis, compared with the control, and that NAC decreased the rate of apoptosis in a dose-dependent manner, suggesting that it had a protective effect against $\mathrm{Cd}$-induced apoptosis.

The mitochondria are an important target of $\mathrm{Cd}$, as mitochondrial dysfunction can cause cellular damage (21). Decreased $\Delta \Psi \mathrm{m}$ is vital in the process of apoptosis, and $\mathrm{Cd}$ can lead to decreased $\Delta \Psi \mathrm{m}$ and Cyt $\mathrm{C}$ release from the mitochondrial membrane, which in turn leads to uncoupling of the mitochondrial respiratory chain. This produces a large quantity of active oxygen species, which are released into the cytoplasm, triggering the downstream apoptotic pathway (22-24). Mao et al suggested that $\mathrm{Cd}$ can increase HEK293 cell permeability, reducing $\Delta \Psi \mathrm{m}$ and triggering mitochondrial dysfunction (25). The mitochondria are central in the process of apoptosis, and loss of $\Delta \Psi \mathrm{m}$ is an important mechanism of inducing apoptosis. Mitochondrial permeability transition pore (MPTP) opening is an important aspect of apoptosis (26). Dorta et al (27) treated extracted liver mitochondria with $5 \mu \mathrm{mol} / 1 \mathrm{Cd}$ for $2.5 \mathrm{~min}$, which triggered loss of $\Delta \Psi \mathrm{m}$, reflecting the fact that the $\Delta \Psi \mathrm{m}$ is sensitive to $\mathrm{Cd}$. In the present study, the $\Delta \Psi \mathrm{m}$ of the Cd-exposed cells decreased significantly, in a dose-dependent manner, compared with the control. Preincubation with NAC effectively inhibited this tendency. $\mathrm{Cd}$ exposure causes mitochondrial membrane damage, reducing $\Delta \Psi \mathrm{m}$ and leading to MPTP opening, enhanced membrane permeability, $\Delta \Psi \mathrm{m}$ loss, and mitochondrial release of apoptosis-inducing factor and Cyt $\mathrm{C}$, triggering the caspase cascade and leading to apoptosis (28-30).

As an energy source, mitochondria are important in cells; mitochondrial damage can lead to disordered cell structure and function. The mitochondria are involved in apoptosis triggered by several stimuli. Yan et al found that $\mathrm{Cd}$ causes mitochondrial swelling, deformation, crest fracture or disappearance, membrane rupture, matrix outflow and vacuole degeneration in nerve cells, and that NAC confers certain protective effects (18). The present study found that Cd caused similar mitochondrial changes, as $12 \mathrm{~h}$ exposure to $10 \mu \mathrm{mol} / \mathrm{l}$ 

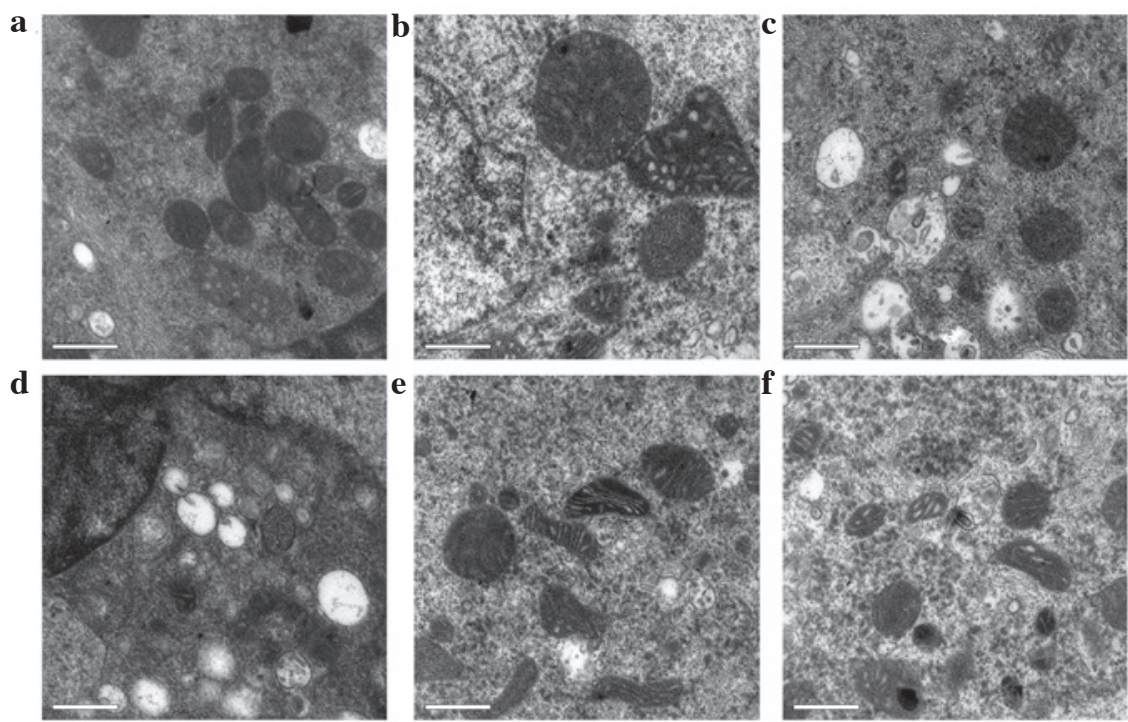

Figure 3. Effect of $\mathrm{Cd}$ and NAC on BRL 3A cell mitochondrial ultrastructure. Cd impaired mitochondrial ultrastructure, with features including loss of cristae, swelling and degeneration, and cell plasma membrane disruption. NAC reduced the mitochondrial swelling induced by $\mathrm{Cd}$. (a) Control; (b) $10 \mu \mathrm{mol} / \mathrm{l} \mathrm{Cd}$; (c) $20 \mu \mathrm{mol} / 1 \mathrm{Cd}$; (d) $40 \mu \mathrm{mol} / 1 \mathrm{Cd}$; (e) $2 \mathrm{mmol} / 1 \mathrm{NAC}$; (f) $2 \mathrm{mmol} / 1 \mathrm{NAC}+20 \mu \mathrm{mol} / 1 \mathrm{Cd}$. Scale bar $=0.5 \mu \mathrm{m}$. Cd, cadmium; NAC, $N$-acetylcysteine.

$12 \mathrm{~h}$

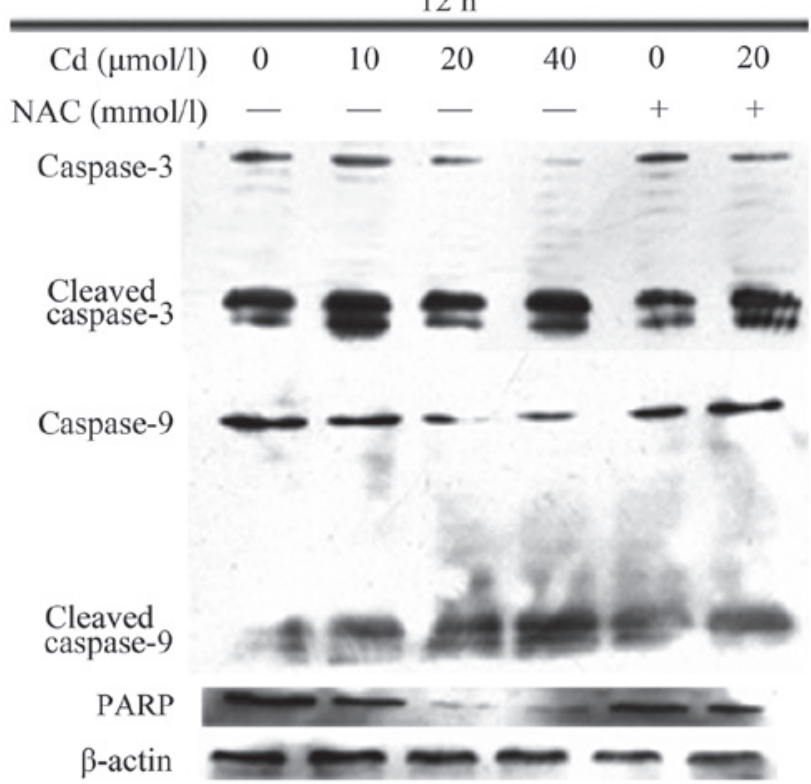

Figure 4. Effect of Cd and NAC on protein levels of caspase-3, caspase-9 and PARP n BRL 3A cells. Cd decreased the protein expression of caspase-3, caspase-9, and PARP, but increased the expression of cleaved caspase- 3 and cleaved caspase-9, as the concentration of $\mathrm{Cd}$ increased. NAC inhibited the Cd-induced changes in the protein levels. $\mathrm{Cd}$, cadmium; NAC, $N$-acetylcysteine; PARP, poly (ADP-ribose) polymerase.

Cd caused marginal mitochondrial cristae fracture, and $12 \mathrm{~h}$ exposure to 20-40 $\mu \mathrm{mol} / 1 \mathrm{Cd}$ eventually caused mitochondrial collapse and vacuolation. NAC preincubation reduced mitochondrial deformation and damage, indicating that $\mathrm{Cd}$ may have caused mitochondrial injury through oxidative damage in the BRL 3A cells.

PARP is a post-translational modification enzyme, which is predominantly present in eukaryotic cell nuclei. Numerous studies have demonstrated that multiple stimuli can lead to activation of the caspase family, cleaving the substrate (PARP)
$12 \mathrm{~h}$

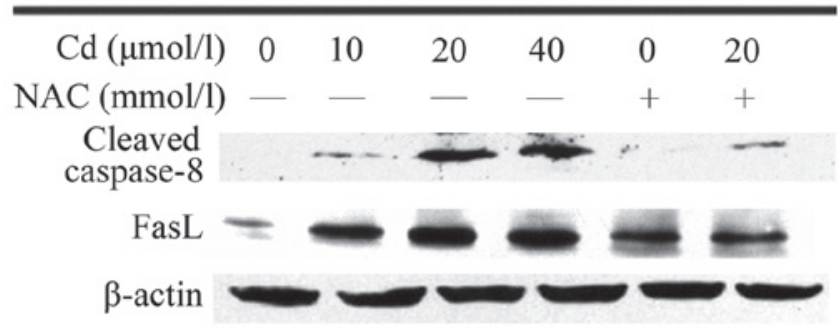

Figure 5. Effect of Cd and NAC on protein levels of caspase-8 and FasL in BRL 3A cells. Cd elevated the protein levels of cleaved caspase- 8 and FasL in a dose-dependent manner. NAC inhibited the Cd-induced increase in these protein levels. Cd, cadmium; NAC, $N$-acetylcysteine; FasL, Fas ligand.

and leading to apoptosis $(31,32)$. Guégan and Sola (33) demonstrated that long-term focal cerebral ischemia in mice following middle cerebral artery obstruction always involves caspase-3 activation; caspase-3 cleaves PARP, leading to the loss of PARP activity, followed by DNA fragmentation and apoptosis. Using a rat acute cerebral ischemia model, Benchoua et al (34) reported that caspase- 8 cleaves PARP and induces apoptosis. Pacher et al $(35,36)$ demonstrated, that in oxidative stress, PARP activation by oxidation damages DNA, and is an important mechanism in promoting cell dysfunction an inhibiting tissue function. The present study demonstrated that $\mathrm{Cd}$ activated PARP precursor cleavage, and that the combined application of NAC reversed this tendency, suggesting that Cd-induced apoptosis in the BRL 3A cells involved PARP activation. As an antioxidant, NAC can alleviate cell damage caused by oxidative stress. Studies have shown that mitochondria coordinate caspase activation through the release of Cyt C due to the outer mitochondrial membrane becoming permeable (37,38). Following its release into the cytoplasm, Cyt C combines with Apaf-1 to form a polyadenylic complex (39). The domain structure can recruit the cytoplasmic caspase- 9 precursor and self-activate, and caspase- 9 can cleave and 
activate the downstream caspases, cleaving their substrates and triggering apoptosis. Caspase- 9 is an important initiator enzyme, which can cleave caspase- 3 and caspase-7, leading to apoptosis. Caspase-3 is a key factor in apoptosis, and is directly involved in the chromosome condensation and DNA fragmentation processes. The present study demonstrated that caspase-3 and caspase- 9 activities were significantly enhanced, and that there was increased caspase- 3 cleavage and protein expression of caspase- 9 as the $\mathrm{Cd}$ concentrations increased. Preincubation with NAC effectively reversed the caspase activation, suggesting that the mitochondrial pathway was an important channel through which $\mathrm{Cd}$ induced apoptosis in the BRL 3A cells.

Fas/FasL are membrane proteins, which are closely associated with apoptosis (40). The induction of caspase-mediated apoptosis through the Fas pathway is an important mechanism by which apoptosis is induced. Fas/FasL-mediated alveolar epithelial cell apoptosis is involved in the process of pulmonary fibrosis (41) and the treatment of pulmonary fibrosis and tumors in rats $(42,43)$. In osteosarcoma cells treated with matrine, cell proliferation is inhibited, triggering apoptosis, increasing the protein expression of Fas/FasL and the activation of caspase-3, caspase- 8 and caspase-9 in a dose-dependent manner, indicating that Fas/FasL protein activation may be involved in inducing apoptosis in tumor cells (5). The present study demonstrated that $\mathrm{Cd}$ increased the protein expression levels of cleaved caspase- 8 and FasL, and that NAC inhibited this increase. Caspase- 8 may be involved in the death receptor pathway of apoptosis induced by $\mathrm{Cd}$. and may be involved in BRL 3A cell apoptosis.

$\mathrm{Cd}$ was found to cause the uncoupling of the mitochondrial respiratory chain, decreased $\Delta \Psi \mathrm{m}$, and led to mitochondrial swelling, degeneration, cristae blurring, deformation and eventual collapse. It also stimulated the activation of caspase-3 and caspase-9, PARP cleavage, and increased the protein expression levels of cleaved caspase- 8 and FasL, leading to apoptosis. NAC exerted an inhibitory effect on the mitochondrial and death receptor pathways involved in $\mathrm{Cd}$-induced apoptosis in the BRL 3A cells, suggesting that it exerts a protective effect.

\section{Acknowledgements}

This study was supported by grants from the Nation Natural Science Foundation of China (grant nos. 31101866 and 31302058) and a project funded by the Priority Academic Program Development of Jiangsu Higher Education Institutions.

\section{References}

1. Bertin G and Averbeck D: Cadmium: Cellular effects, modifications of biomolecules, modulation of DNA repair and genotoxic consequences (a review). Biochimie 88: 1549-1559, 2006.

2. Pham TN, Marion M, Denizeau F and Jumarie C: Cadmium-induced apoptosis in rat hepatocytes does not necessarily involve caspase-dependent pathways. Toxicol In Vitro 20: 1331-1342, 2006.

3. Li Y and Lim SC: Cadmium-induced apoptosis of hepatocytes is not associated with death receptor-related caspase-dependent pathways in the rat. Environ Toxicol Pharmacol 24: 231-238, 2007.

4. Hossain S, Liu HN, Nguyen M, Shore G and Almazan G: Cadmium exposure induces mitochondria-dependent apoptosis in oligodendrocytes. Neurotoxicology 30: 544-554, 2009.
5. Liang CZ, Zhang JK, Shi Z, Liu B, Shen CQ and Tao HM: Matrine induces caspase-dependent apoptosis in human osteosarcoma cells in vitro and in vivo through the upregulation of Bax and Fas/FasL and downregulation of Bcl-2. Cancer Chemother Pharmacol 69: 317-331, 2012.

6. De Flora S, Izzotti A, D'Agostini F and Balansky RM: Mechanisms of $\mathrm{N}$-acetylcysteine in the prevention of DNA damage and cancer, with special reference to smoking-related end-points. Carcinogenesis 22: 999-1013, 2001.

7. Wang HW, Yang W, Lu JY, Li F, Sun JZ, Zhang W, Guo NN, Gao L and Kang JR: N-acetylcysteine administration is associated with reduced activation of NF-kB and preserves lung dendritic cells function in a zymosan-induced generalized inflammation model. J Clin Immunol 33: 649-660, 2013.

8. Rowbotham DS, Wendon JA and Harrison PM: N-acetylcysteine infusion in viral myocarditis: A case report. Int J Cardiol 60: 315-316, 1997.

9. Chen G, Shi J, Hu Z and Hang C: Inhibitory effect on cerebral inflammatory response following traumatic brain injury in rats: A potential neuroprotective mechanism of $\mathrm{N}$-acetylcysteine. Mediators Inflamm 2008: 716458, 2008.

10. Kim J and Sharma RP: Cadmium-induced apoptosis in murine macrophages is antagonized by antioxidants and caspase inhibitors. J Toxicol Environ Health A 69: 1181-1201, 2006.

11. Kalariya NM, Wills NK, Ramana KV, Srivastava SK and van Kuijk FJ: Cadmium-induced apoptotic death of human retinal pigment epithelial cells is mediated by MAPK pathway. Exp Eye Res 89: 494-502, 2009.

12. D'Agostini F, Balansky RM, Izzotti A, Lubet RA, Kelloff GJ and De Flora S: Modulation of apoptosis by cigarette smoke and cancer chemopreventive agents in the respiratory tract of rats. Carcinogenesis 22: 375-380, 2001.

13. El-Sokkary GH, Nafady AA and Shabash EH: Melatonin administration ameliorates cadmium-induced oxidative stress and morphological changes in the liver of rat. Ecotoxicol Environ Saf 73: 456-463, 2010

14. Li R, Yuan C, Dong C, Shuang S and Choi MM: In vivo antioxidative effect of isoquercitrin on cadmium-induced oxidative damage to mouse liver and kidney. Naunyn Schmiedebergs Arch Pharmacol 383: 437-445, 2011.

15. Jia Y, Lin J, Mi Y and Zhang C: Quercetin attenuates cadmium-induced oxidative damage and apoptosis in granulosa cells from chicken ovarian follicles. Reprod Toxicol 31: 477-485, 2011.

16. White RJ and Reynolds IJ: Mitochondrial depolarization in glutamate-stimulated neurons: An early signal specific to excitotoxin exposure. J Neurosci 16: 5688-5697, 1996.

17. Yan Y, Bian JC, Zhong LX, Zhang Y, Sun Y and Liu ZP: Oxidative stress and apoptotic changes of rat cerebral cortical neurons exposed to cadmium in vitro. Biomed Environ Sci 25: 172-181, 2012.

18. Dong S, Shen HM and Ong CN: Cadmium-induced apoptosis and phenotypic changes in mouse thymocytes. Mol Cell Biochem 222: 11-20, 2001.

19. Pathak N and Khandelwal S: Modulation of cadmium induced alterations in murine thymocytes by piperine: Oxidative stress, apoptosis, phenotyping and blastogenesis. Biochem Pharmacol 72: 486-497, 2006.

20. Chen L, Liu L, Luo Y and Huang S: MAPK and mTOR pathways are involved in cadmium-induced neuronal apoptosis. J Neurochem 105: 251-261, 2008.

21. Li M, Kondo T, Zhao QL, Li FJ, Tanabe K, Arai Y, Zhou ZC and Kasuya M: Apoptosis induced by cadmium in human lymphoma U937 cells through $\mathrm{Ca} 2+-$ calpain and caspase-mitochondria-dependent pathways. J Biol Chem 275: 39702-39709, 2000.

22. Ludovico P, Rodrigues F, Almeida A, Silva MT, Barrientos A and Côrte-Real M: Cytochrome $c$ release and mitochondria involvement in programmed cell death induced by acetic acid in Saccharomyces cerevisiae. Mol Biol Cell 13: 2598-2606, 2002.

23. Anuradha CD, Kanno S and Hirano S: Oxidative damage to mitochondria is a preliminary step to caspase-3 activation in fluoride-induced apoptosis in HL-60 cells. Free Radic Biol Med 31: 367-373, 2001.

24. Green DR and Reed JC: Mitochondria and apoptosis. Science 281: 1309-1312, 1998.

25. Mao WP, Zhang NN, Zhou FY, Li WX, Liu HY, Feng J, Zhou L, Wei CJ, Pan YB and He ZJ: Cadmium directly induced mitochondrial dysfunction of human embryonic kidney cells. Hum Exp Toxicol 30: 920-929, 2011. 
26. Li M, Xia T, Jiang CS, Li LJ, Fu JL and Zhou ZC: Cadmium directly induced the opening of membrane permeability pore of mitochondria which possibly involved in cadmium-triggered apoptosis. Toxicology 194: 19-33, 2003

27. Dorta DJ, Leite S, DeMarco KC, Prado IM, Rodrigues T, Mingatto FE, Uyemura SA, Santos AC and Curti C: A proposed sequence of events for cadmium-induced mitochondrial impairment. J Inorg Biochem 97: 251-257, 2003.

28. Li M, Kondo T, Zhao QL, Li FJ, Tanabe K, Arai Y, Zhou ZC and Saduya M: Apoptosisinduced by cadmiumin humanlymphoma U937 cells through $\mathrm{Ca}^{2+}$-calpain and caspase-mitochondria-dependent pathways. J Biol Chem 275: 39702-39709, 2000.

29. Ly JD, Grubb D and Lawen A: The mitochondrial membrane potential $(\Delta \psi \mathrm{m})$ in apoptosis; an update. Apoptosis 8: 115-128, 2003

30. Yuan Y, Jiang CY, Xui H, Sun Y, Hu FF, Bian JC, Liu XZ, Gu JH and Liu ZP: Cadmium-induced apoptosis in primary rat cerebral cortical neurons culture is mediated by a calcium signaling pathway. PLoS One 8: e64330, 2013.

31. Coutant A, Lebeau J, Bidon-Wagner N, Levalois C, Lectard B and Chevillard S: Cadmium-induced apoptosis in lymphoblastoid cell line: Involvement of caspase-dependent and -independent pathways. Biochimie 88: 1815-1822, 2006.

32. Shen HM, Dong SY and Ong CN: Critical role of calcium overloading in cadmium-induced apoptosis in mouse thymocytes. Toxicol Appl Pharmacol 171: 12-19, 2001

33. Guégan C and Sola B: Early and sequential recruitment of apoptotic effectors after focal permanent ischemia in mice. Brain Res 856: 93-100, 2000

34. Benchoua A, Couriaud C, Guégan C, Tartier L, Couvert P, Friocourt G, Chelly J, Ménissier-de Murcia J and Onténiente B Active caspase- 8 translocates into the nucleus of apoptotic cells to inactivate poly (ADP-ribose) polymerase-2. J Biol Chem 277: 34217-34222, 2002
35. Pacher P, Liaudet L, Soriano FG, Mabley JG, Szabó E and Szabó C: The role of poly (ADP-ribose) polymerase activation in the development of myocardial and endothelial dysfunction in diabetes. Diabetes 51: 514-521, 2002

36. Pacher P, Mabley JG, Soriano FG, Liaudet L and Szabó C: Activation of poly (ADP-ribose) polymerase contributes to the endothelial dysfunction associated with hypertension and aging. Int J Mol Med 9: 659-664, 2002.

37. Mao WP, Ye JL, Guan ZB, Zhao JM, Zhang C, Zhang NN, Jiang P and Tian T: Cadmium induces apoptosis in human embryonic kidney (HEK) 293 cells by caspase-dependent and -independent pathways acting on mitochondria. Toxicol In Vitro 21: 343-354, 2007.

38. Kondoh M, Araragi S, Sato K, Higashimoto M, Takiguchi M and Sato M: Cadmium induces apoptosis partly via caspase-9 activation in HL-60 cells. Toxicology 170: 111-117, 2002.

39. Desagher S and Martinou JC: Mitochondria as the central control point of apoptosis. Trends Cell Biol 10: 369-377, 2000

40. Gehring S, Rottmann S, Menkel AR, Mertsching J, KrippnerHeidenreich A and Luscher B: Inhibition of proliferation and apoptosis by the transcriptional repressor Mad1. Repression of Fas-induced caspase-8 activation. J Biol Chem 275: 10413-10420, 2000.

41. Martin TR, Hagimoto N, Nakamura M and Matute-Bello G: Apoptosis and epithelial injury in the lungs. Proc Am Thorac Soc 2: 214-220, 2005.

42. Villa-Morales M and Fernández-Piqueras J: Targeting the Fas/FasL signaling pathway in cancer therapy. Expert Opin Ther Targets 16: 85-101, 2012.

43. Wang W, Zheng Z, Yu W, Lin H, Cui B and Cao F: Polymorphisms of the FAS and FASL genes and risk of breast cancer. Oncol Lett 3: 625-628, 2012. 